\title{
Was the Argentine corralito an efficient measure?: A note
}

\author{
Margarita Samartín *, Clara Cardone, Rodrigo Bustamante \\ Universidad Carlos III de Madrid, Spain
}

Received 15 October 2004; received in revised form 21 July 2005; accepted 6 September 2005

Available online 10 October 2005

\begin{abstract}
Theoretical banking literature has largely explored the role of financial intermediaries in the economy, market failures (banking panics) in the banking sector and the need for bank regulation. However, most models of banking panics and regulation have not been empirically tested.

The Argentine 2001 crisis, with a large deposit withdrawal and the regulation introduced (suspension of convertibility) constitutes a scenario in order to apply some of the theoretical predictions.

In particular, the paper applies Samartín [Samartín, M. (2002). Suspension of convertibility vesus deposit insurance: A welfare comparison. European Finance Review, 6(2), 223-244] to the particular case of Argentina. After the estimation of the most important parameters, the model predicts that suspension of convertibility seems to have been the most efficient intervention measure to stop the massive deposit withdrawals.
\end{abstract}

Keywords: Argentina; Banking panics; Deposit insurance; Suspension of convertibility

\footnotetext{
is This research is partially funded by the Spanish Ministry of Education and Culture, project SEC 20011169 . The authors owe special thanks to three anonymous referees for their very helpful comments in earlier versions of this paper. The advice of Hamid Beladi (the editor) during the reviewing process is also acknowledged.

* Corresponding author. Universidad Carlos III de Madrid, Departamento de Economía de la Empresa, Calle Madrid 126, 28903 Getafe, Spain. Tel.: +34 91 6249647; fax: +34 916249608.

E mail address: samartin@emp.uc3m.es (M. Samartín).
} 


\section{Introduction}

The financial system has traditionally been vulnerable to the problem of bank runs, in which many or all depositors at a bank attempt to withdraw their funds simultaneously. If these withdrawals at a particular bank then spread to many or all banks in the banking system they generate a banking panic, with important consequences on both the financial and the real sector of the economy. ${ }^{1}$

In the 1980s and 1990s several countries experienced banking panics or periods in which their banking systems stopped functioning and these economies evidenced important real effects. ${ }^{2}$ More recently, at the end of 2001, Argentina experienced a banking panic, which resulted in one of the most important financial crisis in its history.

Given the relevance of these recent phenomena, the adequate regulatory design of the financial system has become again an important topic of discussion among politicians, regulators and academics.

From a theoretical perspective, the literature has focused on analyzing the rationale behind the existence of financial intermediaries, the causes of banking panics and the different regulatory measures in order to prevent them (e.g. Allen \& Gale, 1998; Alonso, 1996; Calomiris \& Kahn, 1991; Chari \& Jagannathan, 1988; Diamond \& Dybvig, 1983; Jacklin \& Bhattacharya, 1988; Samartín, 2002, among others ${ }^{3}$ ). This stream of research has approached banking panics through two different types of models.

First, the models of pure panic runs, in which bank runs occur as random phenomena, with no correlation with other economic variables. Diamond and Dybvig (1983), following Bryant (1980), attempted to formalize the notion of liquidity seeking behavior by individuals and its implications for the design of their financing contracts. The paper has important features of real world intermediaries: first, it incorporates the idea that individuals have uncertain preferences, which gives rise to a demand for liquidity. This is combined with a second important feature, namely, real investment projects are irreversible, or at least costly to restart once interrupted and finally, individuals have private information about the realization of their preferred consumption pattern. It is shown that demand deposit contracts, which convert highly illiquid assets into liquid deposits, provide a rationale both for the existence of banks and for their vulnerability to runs. In this framework, the model analyzes two different intervention policies to cope with bank runs. They advocate that if there is no aggregate uncertainty, a suspension of convertibility policy would eliminate the bank run equilibrium. Otherwise, a deposit insurance policy would be more effective.

Diamond and Dybvig' model attracted an important criticism. Gorton (1988), in an empirical study of bank runs in the US during the National Banking Era (1863-1913), found support for the notion that bank runs tended to occur after business cycle peaks, and so they are not the result of "sunspots," as Diamond and Dybvig's model suggests.

Following this idea, a second branch of research asserts that panics are related to the business cycle, which seems to support the empirical evidence. In these models, bank runs occur due to the diffusion of

\footnotetext{
${ }^{1}$ One example of such crises is the Great Depression (1929 1933), which had a significant impact on the banking system of the US, where more than one third of the banks failed (see Gorton and Winton (2002)).

${ }^{2}$ Lindgren, Garcia, and Saal (1996) find that 73\% of the IMFs member countries suffered banking crises between 1980 and 1996.

3 A comprehensive survey of this literature can be found in Gorton and Winton (2002).
} 
negative information among depositors about bank's solvency (e.g., Allen \& Gale, 1998; Alonso, 1996; Calomiris \& Kahn, 1991; Chari \& Jagannathan, 1988; Jacklin \& Bhattacharya, 1988; Samartín 2002). ${ }^{4}$

The paper aims to analyze if the suspension measure implemented in Argentina (corralito) was an efficient tool in order to prevent the banking panic of 2001. The question is tackled by applying the results of Samartín (2002). This measure is compared with deposit insurance, which is usually justified as the regulatory tool that gives stability to the banking system, and avoids banking panics. In this respect, it should be mentioned that Argentina had a private deposit insurance system, which could not avoid the banking panic of 2001.

Although there is a large literature on bank runs, however, not so many papers have done a welfare analysis of regulatory policies. In this sense, we think that Samartín (2002) provides important insights which allow us to understand better how the choice between suspension of convertibility and deposit insurance is related to economic fundamentals such as the relative risk aversion coefficient, the expected return on the bank's assets, and the volatility of returns. These are important insights because they are based on a model in which information-based bank runs (insolvency crises) and runs unrelated to low returns on the banks' assets (liquidity crises) can occur. This is the relevant situation for the Argentine 2001 crisis because Argentina had a solvency problem (absent growth, it lacked the ability to pay) and a liquidity problem (it had substantial amounts of short-term debt to be refunded). Also, the manuscript analyzes how the dispersion of the representative bank's assets returns influences the choice between suspension of convertibility and deposit insurance. The results are particularly relevant for the Argentine crisis because Argentina had a very volatile economy, as shown in Fanelli (2003) for example.

The structure of the paper is as follows: Section 2 presents the analytical framework and provides a welfare comparison between two measures that have traditionally been used by banks in order to prevent runs: suspension of convertibility and deposit insurance. The application of the model for the case of Argentina is carried out in Section 3. Finally, concluding remarks are presented in Section 4.

\section{Analytical framework}

The purpose of this section is to present the analytical framework that will be applied to the case of Argentina. ${ }^{5}$

The model considers a three-period economy and one single commodity. On the consumer side, there exist a continuum of ex-ante identical agents in the interval $[0,1]$ that are endowed with one unit of this consumption good in period 0 . In period 1 , they are subject to a non-observable liquidity shock and they can be either of two types. The difference between types is that type 1 agents $^{6}$ derive relatively more utility from consumption in period 1 with respect to type 2 agents. Individuals have power utility functions, with a constant relative risk aversion coefficient denoted by $\gamma$.

\footnotetext{
${ }^{4}$ It should be mentioned that there are a number of recent papers that study banking panics in the context of the entire banking system (Aghion, Bolton, \& Dewatripont, 2000; Allen \& Gale, 2000; Chen, 1999; Freixas, Parigi, \& Rochet, 2000. A survey of this literature can be found in Gorton and Winton (2002).

${ }^{5}$ For a detailed version of this model see Samartín (2002).

6 The proportion of this kind of individuals is random and takes a value $t_{1}$ with probability $r$ and $t_{2}$ with probability $1 \quad r$ (and $t_{1}<t_{2}$ ). The expected proportion of type 1 agents is denoted by $\bar{t}$.
} 
Table 1

States of nature (Samartín, 2002)

\begin{tabular}{llll}
\hline$\theta_{i}$ & State $\tilde{t} \tilde{\alpha} \tilde{R}$ & Prob. $p\left(\theta_{i}\right)$ & Bank runs \\
\hline 1 & $t_{1} 0 \tilde{R}$ & $r(1 \quad q)$ & No \\
2 & $t_{1} \propto R_{h}$ & $r(1 \quad p) q$ & No \\
3 & $t_{1} \propto R_{l}$ & $r p q$ & Yes \\
4 & $t_{2} 0 \tilde{R}$ & $\left(\begin{array}{lll}1 & r\end{array}\right)\left(\begin{array}{ll}1 & q\end{array}\right)$ & Yes \\
5 & $t_{2} \propto R_{h}$ & $\left(\begin{array}{ll}1 & r\end{array}\right)\left(\begin{array}{ll}1 & p\end{array}\right)$ & No \\
6 & $t_{2} \propto R_{l}$ & $\left(\begin{array}{ll}1 & r\end{array}\right) q$ & Yes \\
\hline
\end{tabular}

It is assumed that a random fraction ( $\tilde{\alpha})$ of type 2 depositors receive a perfectly informative signal about the bank's asset return. ${ }^{7}$ This signal can be interpreted as a relevant economic variable that affects the value of the bank (in contrast to the CAPM this source of systematic risk is not known by all agents). The rest of type 2 individuals do not acquire information and try to infer the state of nature from the behavior of the other agents.

Finally, in period 0 , the bank can invest in a technology that yields a random return $(\tilde{R})$ in period $2 .^{8}$ As mentioned before, this return is affected by an exogenous risk factor (see Table 1). ${ }^{9}$

The time structure of the model is summarized as follows: in period 0, individuals deposit their endowment in the bank and are offered a menu of contracts. In period 1, depositors make their withdrawal decisions. The decision of type 1 consumers is trivial, as they will always withdraw their funds. Informed type 2 individuals will withdraw the deposits when they receive a negative signal and will maintain their funds otherwise. Finally, uninformed type 2 agents behave according to the size of the queue that they observe at the bank. However, this size can be large enough due to both a negative information shock or just to a liquidity shock. This noisy signal may induce the non informed depositors to sometimes erroneously withdraw their funds from the bank. Conditions for both information-induced and pure panic runs to occur are summarized in theorem 1 of Samartín (2002). Bank runs will occur in states 3, 4 and 6. In states 3 and 6, there will be information induced runs, whereas in state 4 we have a pure panic run.

Having established the equilibrium with banking panics, we will compare, from an ex ante point of view, two different intervention measures to cope with runs: suspension of convertibility versus deposit insurance, given their relative benefits and costs (of randomization in meeting liquidity needs, or the liquidity cost of suspension and deadweight taxation associated to deposit insurance). In the case of suspension, it will be desirable when there is no information (state 4) and on the contrary, it will generate a cost in bad states (states 4 and 6) or when some type 1 individuals do not receive the promised consumption level (liquidity cost). For comparative purposes, let $C_{\text {sus }}$ represent the certainty equivalent of the expected utility with suspension. An alternative to suspension of convertibility is to have a full coverage deposit insurance system. This mechanism will remove the incentives of informed individuals to acquire information and hence to run on the bank as they are always assured the promised

\footnotetext{
7 This random variable may take a value $\alpha$ with probability $q$ and 0 with probability $1 \quad q$.

${ }^{8}$ This random variable may take a value $0<R_{l}<1$ with probability $p$ and $R_{h}>1$ with probability $1 p$.

9 The three random variables are assumed to be independently distributed. Together, they describe the state of nature, $\tilde{\theta} \quad(\tilde{t} \tilde{\alpha}$

$\tilde{R})$. Table 1 shows the different states of nature and their associated probabilities.
} 


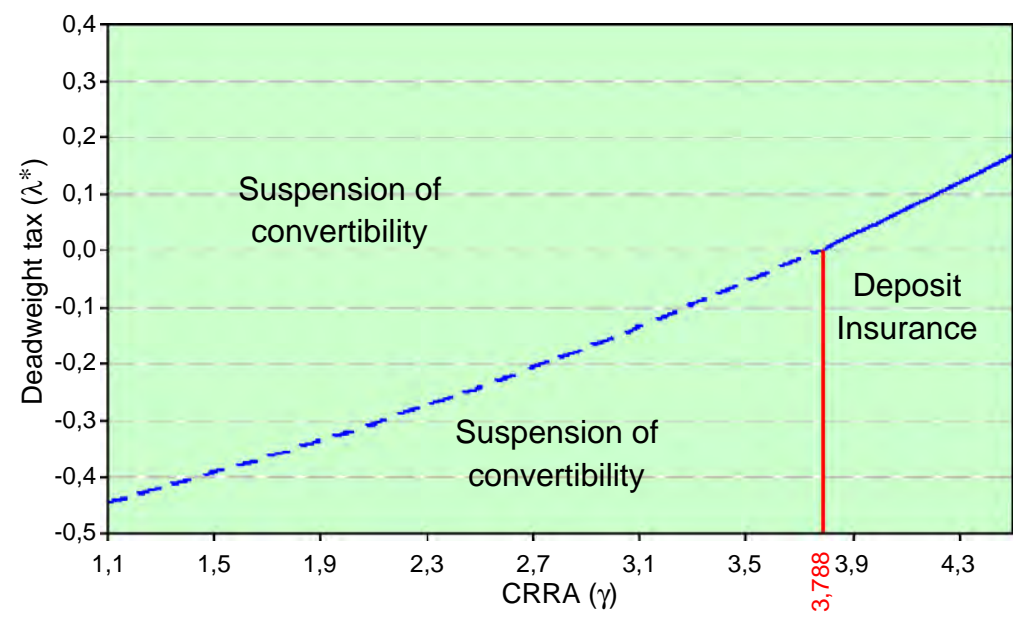

Fig. 1. Suspension of convertibility versus deposit insurance (Samartín, 2002).

(ex ante) consumption level, and will have an utility of $\mathrm{EU}_{\mathrm{dep}}$ (certainty equivalent of $C_{\mathrm{dep}}$ ). However, the deposit insurance has a cost, that is that, whenever the low return is realized, the bank does not have enough funds to pay depositors and other sectors have to supply the difference. Let $\mathrm{EC}_{\mathrm{dep}}$ represent the expected cost of the insurance. Using the Laffont and Tirole (1986) approach, it is assumed that a transfer $\mathrm{EC}_{\mathrm{dep}}$ from the regulatory agent to the bank will generate a social cost of $(1+\lambda) \mathrm{EC}_{\mathrm{dep}}$, where $\lambda$ is a deadweight tax. The welfare measure in the case of a deposit insurance system is $C_{\text {dep }}(1+\lambda) \mathrm{EC}_{\text {dep. }}$. Since $\lambda$ is an exogenous variable to the model, the results are presented as a function of a level of $\lambda^{*}$, for which the two measures deliver the same utility. ${ }^{10}$ Hence, if the value of the deadweight tax is $\lambda^{*}$ percent or lower, the deposit insurance arrangement is best. Otherwise, suspension of convertibility should be preferred.

Some of the conclusions obtained in Samartín (2002) are summarized in Fig. 1. This figure shows the deadweight tax as a function of the relative risk aversion coefficient $(\gamma)$. As it can be observed, for low levels of this coefficient (values below a critical $\gamma^{*}$ ) suspension of convertibility is always best, even though deposit insurance could be provided at zero social cost. This region is interesting as it implies that suspension should be the preferred measure, independently of $\lambda$. This implies that when agents are not very risk averse they do not care as much for the liquidity cost associated to a suspension of convertibility policy. However, as risk aversion increases (above the critical $\gamma^{*}$ ) deposit insurance improves with respect to the suspension measure. As previously mentioned, if the deadweight tax is $\lambda^{*}$ percent or lower, the deposit insurance arrangement is best, otherwise suspension of convertibility is more efficient. The critical $\gamma$ is thus the point for which $\lambda^{*}$ is zero. It can be shown that the critical $\gamma^{*}$, is affected by other exogenous parameters of the model, such as the bank's asset expected return $(R)$, or its dispersion $\left(\sigma^{2}\right)$. Both, a decrease in the dispersion in the bank asset or an increase in its expected return cause a higher value for the critical $\gamma$. Also increasing the expected proportion of type 1 consumers

$\overline{10}$ This means $\lambda^{*}$ should be such that $C_{\text {sus }} \quad C_{\text {dep }} \quad(1+\lambda) \mathrm{EC}_{\mathrm{dep}}$ or equivalently, $\lambda^{*}=\frac{C_{\mathrm{dep}}-C_{\mathrm{sus}}}{E C_{\mathrm{dep}}} \quad 1$. 
increases the critical value. Finally, variations in the proportion of informed agents, or its probability, do not influence the critical $\gamma^{*}$.

\section{Application to the case of Argentina}

The main features of the recent Argentine crisis (i.e., a banking panic, the implementation of a suspension of convertibility policy and the existence of a deposit insurance system), allow us to apply the previously described model to this particular case.

The application requires the estimation of an important parameter that determines the choice of the most efficient policy measure: the relative risk aversion coefficient $(\gamma)$. Other relevant parameters in the analysis are the expected return and the volatility of the bank's asset.

Those parameters have been estimated for the period April 1995 to December 2001 (the six previous years to the crisis). The main reasons for selecting this period are the high sensitivity of the results to variations in the economic environment and the fact that the main features of the financial system in December 2001 were a consequence of the changes experienced after the Mexican crisis in 1994. Finally, the deposit insurance system was re-established in 1995. Hereafter, the values for the most important parameters are estimated.

The analysis is carried out in two steps: First, the critical value of $\lambda^{*}$ for each $\gamma$ is derived (as in Fig. 1). This will also allow us to obtain the critical $\gamma$, or the value of the relative risk aversion coefficient for which $\lambda^{*}=0$. In order to simulate this curve, the following parameters need to be estimated: expected return and volatility of the bank's assets $\left(R, \sigma^{2}\right)$, expected proportions of type 1 agents $(t)$, proportion of informed agents and its probability $(\alpha ; q)$. Regarding the bank's asset expected return and its volatility, they have been approximated by the average and variance of returns for the consolidated banking system. In the period 1995-2001 banks averaged an annual return on assets of about $0.12 \%$ with a variance of returns of $4.16 \%$. Concerning the expected proportions of type 1 agents, different curves have been simulated for different expected proportions of type 1 agents, $t$, that range from 0.1 to 0.8 approximately. Finally, the rest of parameters (proportion of informed agents and its probability), the ones used in Samartín (2002) have been considered. However, as mentioned before, these last parameters do not influence the critical $\gamma^{*}$. The parameters used in these simulations are summarized in Table 2.

Given these values, the simulated curves are shown in Fig. 2, which determine a critical $\gamma^{*}$ of 4.11 (for $t=0.103$ ), 4.184 (for $t=0.302$ ), 4.26 (for $t=0.502$ ) and 4.403 (for $t=0.801$ ).

Second, the relative risk aversion coefficient, in the case of Argentina, is derived.

Regarding the relative risk aversion coefficient, it has been estimated with a particular asset valuation model, like the Consumption Capital Asset Pricing Model (CCAPM) with a power utility function. The analysis approximates the relative risk aversion coefficient using data relative to the market Sharpe Ratio and the volatility of the consumption growth rate in a particular economy (for more details and a formal

Table 2

Numerical data in the case of Argentina

\begin{tabular}{lllll}
\hline $\bar{t}$ & $\alpha$ & $q$ & $\bar{R}$ & $\sigma^{2}$ \\
\hline 0.1 to 0.8 & 0.30 & 0.99 & $0.12 \%$ & $4.16 \%$ \\
\hline
\end{tabular}




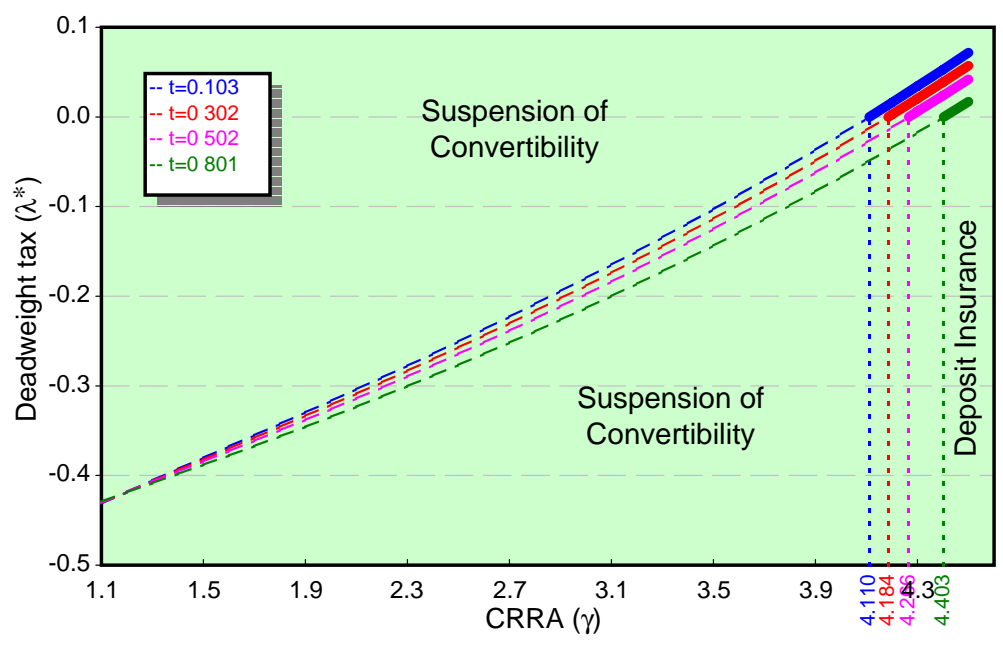

Fig. 2. Simulations in the case of Argentina.

demonstration see Cochrane, 2001). As already mentioned, this proxy assumes a power utility function, as the one used in Samartín (2002) and can be written as:

$$
\left|\frac{E\left(R_{m}\right) \quad R_{f}}{\sigma\left(R_{m}\right)}\right|=\sqrt{ } e^{\gamma^{2} \sigma^{2}\left(\Delta \ln C_{t+1}\right)} \quad 1 \approx \gamma \sigma(\Delta \ln C)
$$

Where:

- $R=$ Expected market return

- $r_{f}=$ Risk free asset return

- $\sigma(\mathrm{RM})=$ Standard deviation of the market return

- $\gamma=$ Relative risk aversion coefficient

- $\sigma(\ln C)=$ Volatility of the consumption growth rate

Hence, isolating the risk aversion coefficient in Eq. (1) it is obtained:

$$
\gamma \approx \frac{\frac{E\left(R_{m}\right) \quad R_{f}}{\sigma\left(R_{m}\right)}}{\sigma(\Delta \ln C)}
$$

As mentioned above, the coefficient is approximated with data relative to the expected market return and its volatility, the risk free rate and the volatility of the consumption growth rate.

The proxy for the market return is the return on the Buenos Aires Stock Exchange General Index (Indice General de la Bolsa de Buenos Aires-IGBBA). ${ }^{11}$ The choice of the risk free rate for Argentina, corresponds to the return on U.S. Treasury Bills with maturity of one year. This choice is due to the lack of a domestic asset that fulfils the required conditions and some features of the Argentine economy in the analyzed period which allowed a wide access to the international capital markets at a relative low cost.

\footnotetext{
$\overline{11}$ See Appendix A for a description of the data used in the analysis.
} 
Among these particular features were the fixed exchange rate established by the Convertibility Law which derived in a dual currency economy, the lack of restrictions to the free international capital flows and the relative low transaction costs to change from one currency to the other.

The average annual real return on the IGBBA for the analyzed period is $4.97 \%$ with a standard deviation of about $33.38 \%$. Since the annual real return on Treasury Bills has averaged $2.5 \%$, the market premium is $2.48 \%$ and the historical market Sharpe Ratio 0.074 . The per capita consumption growth rate has averaged $1.51 \%$ with a standard deviation of about $4.77 \%$. Hence, the relative risk aversion coefficient in the analyzed period is 1.56 .

It is worth mentioning that the market return series are affected by some outlier values. ${ }^{12}$ If those values are eliminated from the sample, the risk aversion coefficient increases to 3.82, due to the higher Sharpe Ratio in absolute terms (increases from 0.074 to 0.18 ). On the overall, the results obtained point out to an approximate variation range: $1.56<\gamma<3.82$.

The estimates of the relative risk aversion coefficient in the case of Argentina are considered reasonable, ${ }^{13}$ and present some evidence against the equity premium puzzle observed in several markets like the American and the Spanish ones, ${ }^{14}$ among others. The equity premium puzzle refers to the inability of the basic asset valuation model with consumption to replicate market premiums compatible with reasonable values of the relative risk aversion coefficient and the observed volatility of the consumption growth rate. The main explanations for this regularity are: a low consumption growth volatility, a high observed market premium and a relative low volatility of the market return.

The estimation of the relative risk aversion coefficient described above ranges from 1.56 to 3.82 . Given that these values are all below the critical values of $\gamma^{*}(4.11,4.184,4.266$ and 4.4403), the model suggests that the suspension measure implemented was the most efficient one, independent on the value of the deadweight tax (even if deposit insurance could have been provided at zero social cost).

\section{Concluding remarks}

This paper attempts to empirically apply the model developed by Samartín (2002), to the particular case of Argentina. This model presents a welfare comparison between two traditional measures to prevent banking panics: suspension of convertibility and deposit insurance.

The features of the recent Argentine crisis (i.e., a general banking panic, the implementation of a suspension of convertibility policy and the existence of a deposit insurance system) constitute an interesting scenario in order to apply the above mentioned model.

Samartín (2002) compares from an ex ante point of view, two different intervention measures to cope with runs: ${ }^{15}$ suspension of convertibility versus deposit insurance, given their relative benefits and costs (of randomization in meeting liquidity needs, or the liquidity cost of suspension and deadweight taxation associated to deposit insurance). The results suggest that when agents are not very risk averse (they have

\footnotetext{
12 Those outlier values were due to the economic stability and the fast development of the capital market generated by the structural reforms implemented: transition to an open economy, privatization of state companies and the pension system, free international capital flows, etc.

13 See Cochrane (2001) and Gollier(2001) for discussions concerning reasonable values of the coefficient.

${ }^{14}$ For a description of the equity premium puzzle in those markets see Cochrane(2001) and Marín and Rubio (2000).

15 No matter the nature of runs, as there can be both information induced and pure panic runs.
} 
a relative risk aversion coefficient below a critical one $\gamma^{*}$, they do not care so much for the liquidity cost and so they would prefer a suspension policy to having a deposit insurance system. On the other hand, as agents become more risk averse (above the critical $\gamma^{*}$ ), they prefer a deposit insurance system to a larger extent. So, a crucial aspect in the application is determining on one hand the critical value of $\gamma^{*}$ for which the critical $\gamma^{*}$ becomes zero, given the parameters of Table 2, and on the other hand, the relative risk aversion coefficient in the case of Argentina.

The estimation of the relative risk aversion coefficient in the case of Argentina ranges from $1.56<\gamma<3.82$, and the estimation of the critical $\gamma^{*}$ for different parameters, gives values above 4.11. These results imply that we fall in the region where the suspension measure gives higher utility, and so these results suggest that the suspension of convertibility implemented turned out to be the most efficient tool.

Finally, several weaknesses of the model should be mentioned. First, the paper relies on a partial equilibrium analysis and so it does not take account of the exchange rate regime. It just implicitly assumes that the bank' return $\tilde{R}$, is affected by some exogenous source of aggregate risk or systemic factor (which could be the exchange rate regime). However, integrating the currency board into the analysis is important to understand the Argentine crisis. This is because a correction of the real exchange rate misalignment implied a solvency problem for the financial system, that was financing private domestic borrowers mainly in dollars. On the other side, those borrowers had incomes that were mostly in pesos. Probably, bank runs were motivated by heterogeneous expectations. Some depositors feared a nominal devaluation and so converted their deposits in pesos into dollars while others feared a pesification. ${ }^{16}$ Another important point might be that different agents could be affected differently by the kind of financial problems which occurred in Argentina. Depositors would probably like deposit insurance since it transfers resources from other sectors of the economy to the depositors. Agents who hold real assets prefer suspension of convertibility because it prevents the redistribution. While not addressed in this paper, these issues represent interesting lines for future research. A final limitation of the paper is that it does not take into account the duration of the corralito. In this respect, Perry and Serven (2003) argue that the deposit freeze had been disruptive because it was held for a long period of time without resolution. They also point out that the crisis had been anticipated for several months. Hence, large and informed depositors had time to withdraw, leaving only small depositors in the banking system.

\section{Appendix A. Data description}

- Per capita consumption growth rate: annualized growth rate of the quarterly series of private non seasonal consumption obtained from National Accounts published by Instituto Nacional de Estadísticas y Censos de Argentina [INDEC]. The population data are also estimates of the INDEC.

\footnotetext{
${ }^{16}$ In this respect an important issue was whether dollarization could have prevented bank runs. For example, De la Torre, Levy Yeyati, and Schmukler (2003) argue that a banking panic was less likely under dollarization. On the other side, Roubini (2001) argues that dollarization could not prevent bank runs because they were basically insolvency based and even if the country decided to dollarize, severe capital and exchange controls, as well as a bank freeze, should have been maintained to have an orderly restructuring of domestic and foreign claims of government, firms, banks and households, i.e. the transition to a dollarized system (even without a final devaluation) would be messy.
} 
- Market return: annualized real return on the monthly series of the Indice General de la Bolsa de Buenos Aires.

- Risk free rate: annualized real return on Treasury Bills (monthly series) with maturity one year published by the U.S Federal Reserve.

- Expected return and volatility of the bank's asset: average return on assets (ROA) and variance of returns estimated from monthly data from the consolidated balance sheet of the financial system (Banco Central de la Republica Argentina).

\section{References}

Aghion, P., Bolton, P., \& Dewatripont, M. (2000). Contagious bank failures in a free banking system. European Economic Review, 44, 713718

Allen, F., \& Gale, D. (1998). Optimal financial crises. Journal of Finance, 53, 12451284.

Allen, F., \& Gale, D. (2000). Financial contagion. Journal of Political Economy, 108(1), 133.

Alonso, I. (1996). On avoiding bank runs. Journal of Monetary Economics, 37, 7387.

Bryant, J. (1980). A model of reserves, bank runs and deposit insurance. Journal of Banking and Finance, 4, 335344.

Calomiris, C. W., \& Kahn, C. M. (1991). The role of demandable debt in structuring optimal banking arrangements. American Economic Review, 81(3), 497513.

Chari, V., \& Jagannathan, R. (1988). Banking panics, information and rational expectations equilibrium. Journal of Finance, 43(3), 749761.

Chen, Y. (1999). Banking panics: The first come, first served rule and information externalities. Journal of Political Economy, 107, 946968.

Cochrane, J. (2001). Asset pricing. Princeton University Press.

De la Torre, A., Levy Yeyati, E., \& Schmukler, S. (2003). Beyond the bipolar view: The rise and fall of Argentina's currency board. Economía, 5(2).

Diamond, D., \& Dybvig, P. (1983). Bank runs, deposit insurance and liquidity. Journal of Political Economy, $91(3), 401419$.

Fanelli, J. M. (2003). Growth, instability and the crisis of convertibility in Argentina. In Teunissen, \& Akkerman (Eds.), The crisis that was not prevented. FONDAD.

Freixas, X., Parigi, B., \& Rochet, C. (2000). Systemic risk, interbank relations and liquidity provision by the central bank. Journey of Money, Credit and Banking, 32(3), 611638.

Gollier, C. (2001). The economics of risk and uncertainty. MIT Press.

Gorton, G. (1988). Banking panics and business cycles. Oxford University Press.

Gorton, G., \& Winton, A. (1988). Financial intermediation. In G. Constantinides, M. Harris, \& R. Stulz (Eds.), Handbook of the economics of finance. Amsterdam.

Jacklin, C., \& Bhattacharya, S. (1988). Distinguishing panics and information based bank runs: Welfare and policy implications. Journal of Political Economy, 96, 568592.

Laffont, J. J., \& Tirole, J. (1986). Using cost observation to regulate firms. Journal of Political Economy, $94(3), 614$ 641.

Lindgren, C., Garcia, G., \& Saal, M. (1996). Bank soundness and macroeconomic policy. International Monetary Fund.

Marín, J. M., \& Rubio, G. (2000). In Antoni Bosch (Ed.), Economia financiera.

Perry, G., \& Serven, L. (2003). The anatomy of a multiple crisis: Why was Argentina special and what can we learn from it. World Bank Policy Research Working Paper, 3081, 103123.

Roubini, N. (2001). Should Argentina dollarize or float? The pros and cons of alternative exchange rate regimes and their implications for domestic and foreign debt restructuring/reduction. Mimeo. New York University.

Samartín, M. (2002). Suspension of convertibility versus deposit insurance: A welfare comparison. European Finance Review, $6(2), 223244$. 